\title{
Virtual Autopsy in Legal Medicine: Literature Review and Example of Application on the Mummified Remains
}

\author{
IVANa KRUŽIĆ, IVAN JeRKović, Frane Mihanović, ANA MaruŠić, \\ ŠIMUN ANĐELINOVIĆ \& ŽELJANA BAŠIĆ
}

\begin{abstract}
The virtual autopsy and post-mortem imaging methods are relatively novel methods used in medicine to determine cause and manner of death. They can also be exceptionally useful in the process of identification. Although they have numerous advantages, they are still not implemented in practice to a sufficient extent because the methodology has not yet been validated, and studies that deal with legal and practical implications of those methods are relatively scarce. In this article we describe basic principles and advantages of the methodology, explore related legal and practical issues, and present a case of virtual autopsy in practice on the mummified remains of St. Ivan Olini from Church of St. Blaise in Vodnjan (Croatia).
\end{abstract}

Keywords: - Virtual Examination - Autopsy - MSCT • Paleopathology $\bullet$ Mummy $\bullet$ Sacral Remains •

CORRESPONDENCE ADDRESS: . Ivan Jerković, ML, University of Split, University Department of Forensic Sciences, Ruđera Boškovića 33, 21000 Split, Croatia, e-mail: ijerkovic@ unist.hr. Ivana Kružić, PhD, Assistant Professor, University of Split, University Department of Forensic Sciences, Ruđera Boškovića 33, 21000 Split, Croatia, e-mail: ivana.kruzic@unist.hr. Frane Mihanović, PhD, Assistant Professor, University of Split, University Department of Health Studies, Ruđera Boškovića 33, 21000 Split, Croatia, e-mail: frane.mihanovic@mefst.hr. Ana Marušić, PhD, Full Professor, University of Split, Split School of Medicine, Department of Research in Bioimedicine and Health, Šoltanska 2, 21000 Split, Croatia, e-mail: ana.marusic@mefst.hr. Šimun Anđelinović, PhD, Full Professor, University of Split, Rector's Office, Poljička 35, 21000 Split, Croatia, e-mail: simun.andjelinovic@unist.hr. Željana Bašić, PhD, University of Split, University Department of Forensic Sciences, Ruđera Boškovića 33, 21000 Split, Croatia, e-mail: zeljana.basic@unist.hr. 
DOI https://doi.org/10.18690/ml\&s.11.2.67-90.2018

ISSN 2463-7955

(C) 2018 University of Maribor Press

Available at http://journals.um.si/ 
In the most general sense, an autopsy is considered as an internal and external examination of a dead body with the aim of revealing the cause of death (Fernando, 2008). There are usually two main purposes to conduct an autopsy: forensic and clinical/medico-legal. In the clinical context, the main objective of an autopsy is to discover how a patient has died, but it has been also used for decades as a crucial tool in the process of teaching and training medical students. Unlike the clinical autopsy, a medico-legal autopsy has many objectives, including identification, estimation of the time of death, analysis of the injuries (identification, documentation, and assessment of their importance), identification of natural diseases, identification of poisons, as well as identification of medical treatments (Payne-James et al., 2014). A primary component of an autopsy is the dissection of a body, which not only can very often be traumatic for the family of the deceased, but also can be unwelcome or even forbidden in different cultural and religious settings (Krentz et al., 2016; Mohammed \& Kharoshah, 2014; Payne-James et al., 2014; Thali et al., 2009). In some situations, an autopsy is performed when there is no objective need for performing it, whereas, on the other hand, sometimes it is necessary but not sufficient to only perform an autopsy to obtain all information needed. Therefore, many countries in modern times employ advanced nondestructive imaging techniques commonly used in every-day diagnostic procedures that can provide a number of additional data and sometimes even replace the conventional autopsy (Thali et al., 2009; Payne-James et al., 2014).

The most important type of post-mortem imaging is "virtual autopsy" (also known as Virtopsy ${ }^{\circledR}$ ), coined by Prof. Richard Dirnhofer from Bern University (Wirtschaft, 2001). Virtual autopsy uses 3D imaging as opposed to the visual examination of the body. To accomplish internal examinations of the body, the virtual autopsy uses multi-sliced computed tomography and/or magnetic resonance imaging and/or surface scanning techniques, whereas for other types of testing it can employ postmortem angiography or biopsy using the robot. Like traditional autopsy, the aim of virtual autopsy is to assess injuries, the cause and manner of death, and identity (Schweitzer et al., 2014; Thali et al., 2009). However, it has a potentially broad application in the modern era where numerous objections to traditional, invasive autopsy are lodged on legal, ethical and religious grounds (Thali et al., 2009).

There are numerous advantages to the virtual approach. First, the virtual autopsy is a non-destructive method of examination, so that relatives of the deceased are more likely to accept this kind of post-mortem examination, especially because it overcomes many ethical and religious considerations. Second, in contrast to the traditional autopsy, use of virtual autopsy allows for the acquisition of data that is not dependent upon one examination and examiner, i.e., on the experience and methodology of dissection techniques. Third, use of virtual autopsy allows for the collected data to be standardized. Fourth, another major benefit of virtual autopsy 
is that it allows the possibility of an unlimited number of experts to be involved from any part of the world. Fifth, in additional to opening up the possibility for international cooperation on the part of various experts in the field, virtual autopsy also allows for the possibility of reopening the case when the body is buried or cremated. Lastly, virtual autopsy can be useful for other forensic purposes, as it can be partially applied also on the living victims. virtual "autopsy" is particularly useful for analyses when the injuries are healed (Bolliger \& Thali, 2015; van Kan et. al., 2017).

Application of MSCT, often called post-mortem CT (pmCT) in this context (Blum et al., 2018), is nearly synonymous with the virtual autopsy procedure. In practice, MSCT scanning is most often applied to all methods that are included in virtual autopsy (Zimmermann, 2011). The major strength of CT is the possibility of locating and visualizing fractures, foreign bodies, accumulation of fluids, and gases (Blum et al., 2018; Bolliger \& Thali, 2015; Makino et al., 2017). It is also important in postmortem ballistic analysis, as it enables analysis of_injuries, as well as bullet path within and outside the the body (Garetier et al., 2017; Tuchtan et al., 2017; van Kan et al., 2017). Moreover, CT is used to perform angiography in order to visualize traumatic vascular pathologic conditions, as well as to identify and diagnose various cardiovascular diseases, and can reveal numerous natural causes of death as well (Ross et al., 2014).

MRI, on the other hand, can be used in situations where CT has certain inherent limitations; namely, in the examination of soft tissues and organs. In comparison to the CT, MRI can more clearly identify various pathologies as well as injuries located on the soft tissue (Bolliger \& Thali, 2015; Ling, 2010).

Post-mortem biopsy and surface scanning are also integral parts of the full virtual autopsy procedure. Post-mortem biopsy is usually performed for sampling the organ parts for histological analyses, but it can also be employed for sampling tissues and fluids necessary for microbiological and/or toxicological analyses. Another advantage of post-mortem biopsy is that it uses the robot for sampling, thus decreasing the possibility of infection (Bolliger \& Thali, 2015). Surface scanning, on the other hand, has distinct advantages since it can provide valuable information and can be especially useful for accurate depiction and three-documentation of the body surface in real color (Bolliger \& Thali, 2015; Ebert et al., 2016).

Virtual autopsy methods have a special role in the forensic context when the identity of the person is not known and the remains are skeletonized, putrefied or mutilated, or in cases of mass disasters, as they can provide identification data and enable analyses of injuries (Dedouit et al., 2014b). 
Identification can be conducted by the comparison of post-mortem and ante-mortem data. The most useful approach is dental image comparison or comparison of specific anatomical structures, such as frontal sinuses, normal variations on the skeleton, degenerative changes on the bones, healed (ante-mortem) fractures, calcifications, congenital, and other types of abnormalities and diseases (Bolliger \& Thali, 2015; Dedouit et al., 2014b, Ebert et al., 2016; Gascho et al., 2018; Thali et al., 2010;). If ante-mortem images are not available, the only solution is a reconstructive identification, which is basically the process of constructing one's biography based on anatomical features and anthropological standards. This process usually consists of an estimation of sex, age at death, population affinity, and average stature but it can also include an examination of specific pathological and traumatic changes, as well as normal variations (Dedouit et al., 2014b; Iscan \& Steyn, 2013; DiMaio \& Francis, 2001).

Another identification means also is to examine foreign bodies such as surgical devices or implants. Those materials include prostheses, peacemakers, wires, plates, screws, etc. (Bolliger \& Thali, 2015). The detection, location, and visualization of foreign bodies are of great importance in forensic science not only because this is essential for the reconstruction of the event and analysis of injuries but also because it allows for the examination and visualization of material evidence. Furthermore, images and 3D models can provide very accurate dimensions of the objects, which is of special importance in cases of evidence that has identification value, e.g. bullet fragments. MSCT images can also reveal the type of material the analyzed objects are comprised of and thus provides potentially useful evidence in forensic matters. It accomplishes this by measuring radiopacity, i.e. a relative inability of radiation to pass through a specific material ( $\mathrm{Liu} \& \mathrm{He}$, 2018). Most importantly, all of the abovementioned analyses and procedures can provide data not only without destroying the evidence but also even without touching the evidence (Bolliger \& Thali, 2015). Recently, (Baier et al., 2017) showed that important evidence can be printed on 3D printers, and those models can be used as demonstrative evidence in court. In their case, they used a CT scan of the victim's skull to make a printable model they presented at the trial to demonstrate the injuries and the type of weapon used. As scans obtained by virtual autopsy can also be easily converted to 3D models, this example shows a great potential of combining virtual autopsy with 3D printing technologies in the future. These scans could be used to examine not only crucial body parts, like in the above case, but also a wide variety of forensic physical evidence like weapons and bullet parts.

An additional benefit of using the virtual autopsy in court is the fact that it can reduce the negative impact of exhibiting disturbing photos on the family, jurors, and judges (Bolliger \& Thali, 2015). Virtual autopsy visualization also has the salutary benefit of improving and easing communications between legal experts and forensic scientists. In that way, forensic experts can present complex findings using 3D illustrations or animations, in a fashion which is much more comprehensive than 
using traditional autopsy methods, while at the same time being simpler and more easily understood by those who are not familiar with a particular scientific field or methods (judges, jurors, lawyers etc.) (Zimmermann, 2011).

Virtual autopsy and post-mortem imaging methods are usually perceived as alternatives to traditional medico-legal autopsies. However, their application can be much more expansive if we consider that virtual autopsy can be used in tandem with the real autopsy so as to capture the benefits both methods have to offer. Virtual autopsy is particularly useful in cases involving decomposition or complex fractures because this method preserves the integrity of anatomical structures. On the other hand, in cases of gas embolism, virtual autopsy can provide valuable information not only on the presence of the gas but also its distribution and amount (Bolliger and Thali, 2015). Virtual autopsy can be used before an autopsy along with external examination to determine if there is actual need to perform an autopsy in a particular case (Zimmermann, 2011).

Therefore, virtual autopsy, conducted completely or partially, can evidently provide valuable data for both the forensic sciences and the legal system. Nevertheless, unlike traditional forensic methods, and despite its many benefits and advantages over the traditional autopsy, as previously discussed in this paper, virtual autopsy is still relatively underrepresented in forensic and legal literature. Thus, it is not widely known to what extent the methods of the virtual autopsy are applied in practice and whether they are accepted in different legal systems. Also, even though procedures and potential applications are elaborated upon in the literature, the authors could not locate many examples of complete cases. This lack of literature makes it difficult for scientists and practitioners without experience in virtual autopsy to gain sufficient knowledge and critical insight into the application of its methods.

In this article, we aim to explore the extent to which methods included in the virtual autopsy are actually employed in practice, accepted and included in the law and regulations. A further goal of the study is to provide a concrete example of the application of the methodology and to show principles of virtual autopsy in practice, particularly in cases with greater time lapse. In the first part of the paper we will analyse legal context and practice, whereas, in the second part of the paper, we will present the case of the virtual autopsy on the mummified remains of St. Ivan Olini. 


\section{Examples of virtual autopsy application in Europe: legal context and practice}

Virtual autopsy, in some form, is performed across the globe. Although the form can vary depending on the country and specifics of a case, in most cases the prevailing method of choice is CT imaging. This can be achieved by post-mortem $\mathrm{CT}$ (pmCT), a device specially designed for this type of examination but also very often in everyday work on in-hospital devices. Virtual autopsy/post-mortem imaging can, in theory, serve as a substitute for the traditional autopsy. In practice, however, it usually is employed to help determine whether an autopsy is truly necessary (Zimmermann, 2011). Currently, the only literature the authors located that provides an overview of the application and legislation regarding the virtual autopsy is an article by Zimmermann (2011), who conducted a comprehensive analysis and contacted many experts from different countries to provide necessary information. Here, we will briefly summarise the most important findings that cover the topic and will provide information about virtual autopsy in the European framework.

Switzerland, the country where the virtual autopsy method was born, has been a leader in post-mortem imaging (Zimmermann, 2011). In fact, Bern is, to the best of our knowledge, the only place where virtual autopsy with all included procedures is implemented (pmCT, pm CT angio, pmMRI, pm biopsy, and surface scanning). However, virtual autopsy is utilized more frequently in health research than in practice, where it is reserved only for special cases. In practice, pmCT is performed along with autopsy as an adjunct method, i.e., when a responsible person has already decided that there is a need for an autopsy. In criminal trials in Switzerland, imaging has already been accepted as reliable and therefore admissible evidence in several forensic cases (Zimmermann, 2011; Nissan, 2012).

In Denmark, CT imaging usually supplements an autopsy in all cases involving unknown or suspected death. Sweden employs a similar practice, but not all cases include pm imaging. Also, many other European forensic institutes, like those in France, use in-hospital CT and perform imaging, but only as an adjunct to autopsy (Zimmermann, 2011).

On the other hand, some countries perform forensic imaging as a triage for an autopsy, i.e. to determine if a specific case needs an autopsy. In Germany, for example, CT imaging is in some cases a part of the external inspection that usually proceeds an autopsy. Based on the information provided by those two methods together, a practitioner can make the decision whether to perform an autopsy or not. The pm imaging sometimes can also replace traditional autopsy, but it is particularly common in cases of sudden infant death syndrome (SIDS) (Zimmermann, 2011). 
In the United Kingdom, the pm imaging methods can be used as a triage, but they also are performed in the majority of cases involving suspicious deaths in tandem with an autopsy. Also, sometimes they can be an alternative to the classical autopsy, most commonly in high risk cases such as HIV or other infections (Zimmermann, 2011). Recently, post-mortem imaging techniques have been used in investigating pediatric forensic deaths (non-accidental injuries and sudden unexpected deaths in infancy), as well as in perinatal autopsies (Arthurs et al., 2017).

Italy makes available the possibility of performing routine post-mortem imaging as a triage and the prosecutor can authorize pathologists to conduct post-mortem imaging to supplement an autopsy. Interestingly, in mass fatality cases that include more than ten victims, post-mortem imaging techniques such as CT and MRI have already replaced the traditional autopsy (Zimmermann, 2011).

Although medical practitioners have recognized the usefulness of virtual autopsy and post-mortem imaging, the legal systems in most of the countries have been slow to recognize that trend. That is to say, while those methods are not specifically forbidden by law in most countries, nevertheless they are not specifically mentioned in regulations either. Commonly, when regulations mention autopsy, they allow for the possibility of implementation of other methods along with autopsy, but regulatory language employs vague terminology such as "additional" or "other" methods and we could locate no laws or regulations that specifically discuss usage of post-mortem imaging or virtual autopsy, despite the fact that imaging techniques like X-ray images have been used as evidence for decades (Zimmermann, 2011; Thali et al., 2010).

Zimmermann (2011) also draws attention to numerous issues that may stem from the law not being sufficiently developed in this area, thus leading to a legal vacuum of sorts, such as issues pertaining to personal rights, informed consent, data privacy, and proper methods of storing imaging material. Trumping those issues, however, is probably the question of the acceptance or admissibility of post-mortem imaging techniques in court, particularly in cases when the report of findings includes only the stand alone results of imaging analysis without classical autopsy having been performed. Also, sometimes the lack of legal structure and framework can hamper this type of analyses as there is no particular legal basis that would form the basis for a request for some of the post-mortem imaging procedures discussed above in a criminal investigation.

In Croatia, for example, while The Law on Health Protection (Official Gazette $82 / 13$ ) prescribes specific cases when the autopsy is mandatory, it fails to provide any details about the specific procedures to be used. The Rulebook on the Examination of the Dead and Determination of Time and Cause of Death (Official Gazette 46/11) regulates autopsy in somewhat more detail, but only to the extent 
that it defines who can conduct an autopsy, what documents are necessary, and the form of those documents. However, the Regulation does not specify the form the autopsy procedure should take. Accordingly, not only is the Regulation silent on issues pertaining to virtual autopsy, post-mortem imaging, and other supplementary methods, but additionally the Regulation contains no descriptions of the "traditional" autopsy procedure either. Although Regulations do not mention novel or additional methods related to the autopsy, according to Croatian legislation and practice, the court has the discretion to accept any method that can aid in the trial (if they are not specifically forbidden). However, we do not have sufficient data to inform us on the question of the number of medical and legal medicine examiners that rely upon this technology to present their opinion to the court. However, to the best of our knowledge, there is no systematic education of law enforcement agencies about the many benefits and advantages that virtual autopsy can provide.

In order to contribute to the development and acceptance of these alternative methods in the legal system it is crucial to raise awareness of their existence and utility and to provide a comprehensive and complete example of the implementation of their methodology in practice. As we are not able to present actual forensic cases due to legal restrictions and data privacy protection, in the following chapter we will present the case of a virtual autopsy on the mummified body of St. Ivan Olini and describe the methodology used and the results obtained.

Virtual autopsy of St. Ivan Olini

\subsection{Background}

As previously mentioned, a virtual autopsy can be performed not only immediately after a person has died but also after some time period post death. The lapse of time can be months or years, but as we shall see, sometimes can be even centuries and millennia. Research on historical cases support this claim (Mihanović et al., 2017; Appleby et al., 2015; Dedouit et al., 2014a; Kristóf et al., 2015) but especially interesting cases are those of the remains with mummified tissues, as the preserved soft tissue and skeletal remains allow for the evaluation of pathological findings and assessment of the probable cause of death. For example, the study of a young male mummy from Peru revealed him to be a part of a sacrifice ritual (Cobo, 2010). Radiographs of a mummy of an infant from the Pachacamac site in Peru revealed the presence of a stone knife in the neck base (Eeckhout \& Owens, 2008). Additionally, research on an Egyptian mummy demonstrated the usefulness of an MSCT for investigating the method of mummification (Jackowski et al., 2008). One of the most interesting cases from the historical and forensic viewpoint was the case of King Tutankhamun, where the methodology used for analysis revealed additional important information. Namely, a previous historical hypothesis that he died in a battle was rejected as no perimortem trauma was found on MSCT images. Furthermore, researchers discovered that he suffered from several disorders such as 
bone necrosis, Köhler disease II, clubfoot and oligodactyly. The possible cause of death was a consequence of a leg fracture that could had been caused by a fall, and which could progress and be lethal in combination with his malaria infection (Markel, 2010; Hawass et al., 2010).

The mummies of special interest are those of saints, due to growing interest from religious groups, and for cultural, and heritage reasons. Mummified bodies of saints can be attributed to three historical periods: ancient Roman time, the Middle Ages and modern times. Mummies from the Roman period are mostly in the form of body parts, whereas medieval mummies are usually fully preserved. It is believed that mummification of most of the medieval mummies was natural due both to favourable conditions in catacombs as well as the burial ritual with balms (Petaros et al., 2012). In the modern period, the bodies have mostly been subjected to artificial mummification in order to preserve the bodies for religious purposes (Fulcheri, 1996). The majority of mummified saint bodies in Europe are located in geographic areas with strong Christian heritage, mostly in Italy, but also in Spain and Portugal. As Italy and Croatia are sharing their borders on the Adriatic Sea, it is not surprising that throughout history some of the mummies had been transferred to Croatia. An example of such a transfer can be found in the church of St. Blasius in Vodnjan, which curates both the mummified bodies of saints as well as mummified body parts. These mummified bodies were transferred to Croatia from Italy by the painter and collector Gaetano Gressler (Del Ton, 1929) during the French revolution. Gressler left the collection as a permanent heritage to the church and the municipality, under the contract with the pontiff of the parish church of St. Blasius and city authorities in 1818. In 2009, the mummified bodies of the saints were brought to the University of Split and Clinical Hospital Center in Split, Croatia, for the purpose of radiographical examination. In our study, we tested the forensic imagining approach on mummified remains of St. Ivan Olini and performed a virtual autopsy of the body.

\subsection{Choice of the imaging methodology}

We took several radiographic methods into consideration before radiographic imaging. The first method was two-dimensional digital radiographic imaging, which often serves as an imaging technique in radiological studies of mummies (Lynnerup, 2010; Cosmacini \& Piacentini, 2008). The advantage of this method is that it can be performed using mobile equipment (mobile x-ray unit, phosphor plate, digitizer), so x-ray examination could be made inside the church premises. But this method would not be useful to obtain a 3D image and the assessment of the state of preservation of soft tissues. The second method of choice was magnetic resonance imaging (MRI). For this methodological approach, the remains would need to be taken out of the sarcophagi where they were stored in. Although it is often thought that mummified tissue could not be studied using MR imaging because of the low 
water content in mummies, ultrashort echo time technique proved to be useful in the evaluation of mummified tissue (Öhrström et al., 2013; Panzer et al., 2013a). However, the major limitation to this technological approach was the possible presence of the metal parts usually stored along with relics of saints (Mihanović et al., 2017).

The third method taken into consideration was an examination by the MSCT (Bushong, 2013). Although there is a possibility of using a mobile MSCT device, we ultimately rejected this approach because of its high cost. An advantage of MSCT is that it provides superior details of the anatomic structures, mainly because of its higher spatial resolution (Öhrström et al., 2013). To acquire high-quality imaging, the MSCT device has to fulfil minimal technical characteristics, such as the spatial resolution of $25 \mathrm{lp} / \mathrm{mm}$ (line pair per millimetre) and the possibility of archiving raw data. Multidetector computed tomography offers a detailed noninvasive analysis of objects on/in the mummies with 3D imaging and it is frequently used in the study of mummies (Saleem \& Hawass, 2014; Davey et al., 2013; Panzer et al., 2013b; Dedouit et al., 2010; Jackowski et al., 2008). MSCT provides a reconstruction of the axial tomographic plane using a computer by multiple measurements from several hundred projections during a single rotation of $360^{\circ}$. By movement of the table during imaging and the rotation of the $\mathrm{x}$-ray tube and detectors, a volumetric or spiral scanning data is acquired, enabling the evaluation of data from the volume of the scanned object (Pettersson \& Allison, 1998).

\subsection{Transport and storing}

As the degree of preservation of mummified remains was not known and had yet to be analyzed, the transport of the remains was the most hazardous part of the study. The transport and preparation for examinations needed careful preparation in order to prevent further damage to the bodies and to enhance the possibility of proper radiographic imaging.

For the purpose of the transport of the mummified saint bodies, the wooden coffins were made in specific measurements that allowed passing of the casket through the MSCT device (open bore: $70 \mathrm{~cm}$ ). The coffins were made by the Croatian Restoration Department. Also, a thin wooden laminate was prepared in order to transfer the bodies from the sarcophagi to coffins without contact and destruction of the material. 


\subsection{St. Ivan Olini's biography}

The mummified body evaluated in this study is that of St. Ivan Olini. He was born in Venice in 1225 and became a priest at the age of 43 . He was especially engaged at the time of the plague, as he helped the ill and the dying. After his death in 1300, his body was buried in a sarcophagus. His body was later transferred to the church of St. Sebastian. In 1400 Pope Bonifacie IX made a declaration which is still kept by the side of the Olini mummy. Francesco Bembo, the Venice bishop, formalized the worship of Olini in the church of St. Sebastian and worshiping permission also confirmed the patriarch Giovanni Tiepolo in 1622 (Del Ton, 1929; Jelenić, 2000).

\subsection{Imaging procedure and analysis}

The examination was performed on an MSCT device, Somatom 16 (Siemens, Erlangen, Germany), which has 16 rows of detectors and the spatial resolution of $30 \mathrm{lp} / \mathrm{mm}$. The body was spirally screened in two acts due to coffin length of 200 $\mathrm{cm}$. Scanning parameters were: $120 \mathrm{kVp}, 162 \mathrm{~mA}$, protocol name - Body Angio Routine, Convolutional Kernel B30f. The slice thickness of acquisition slices was $16 \times 0.75 \mathrm{~mm}$, and were afterward reconstructed to $2-\mathrm{mm}$-slice thickness for $2 \mathrm{D}$ images. All data was stored on a CD, and the database in the device was deleted afterward. Using software DICOM viewer, Osirix v.3.9.4 (Pixmeo, Geneva, Switzerland) 2D images were post-processed with Multiplanar reconstruction (MPR) and Volume Rendering Techniques (VRT). Also, we analyzed the values of Hounsfield Units (HU) on different locations through the entire scan so as to differentiate bones, remains of the soft tissue, other materials and artifacts. The Hounsfield scale shows "relative densities determined by CT". On the Hounsfield scale, water is defined with $0 \mathrm{HU}$, whereas the air is defined with $-1000 \mathrm{HU}$ (Johnson et al., 2014).

After the reconstruction, an interdisciplinary team reviewed the images and drew the conclusions about the mummification process, its state of preservation, preserved anatomical structures, and pathological findings. The interdisciplinary team consisted of one radiology expert, three biological anthropologists, one anatomist, and one pathologist/court medicine examiner. The decisions on final interpretations were made by consent.

\subsection{Results}

All CT values of soft tissues were negative and smaller than those of an unmummified body with water-containing soft tissues. The examination of the anatomical structures revealed that the remains of internal organs were preserved. Brain tissue remains (CT values-505 HU) were visible on the inner surface of the parietal bones because of the body position - lying on the back with the head 
I. Kružić, I. Jerković, F. Mihanović, A. Marušić, Š. Anđelinović, Ž. Bašić:

Virtual Autopsy in Legal Medicine: Literature Review and Example of

Application on the Mummified Remains

positioned on the left side (Figure 1). The remains of the lungs and other internal organs were also visible and were positioned on the posterior and/or distal side due to post-mortem body position. VRT 3D method revealed that the ligaments were preserved and were well visible particularly near joint surfaces. The remains of all major muscular groups were also preserved. Blood vessels were clearly visible, especially arteries and veins.

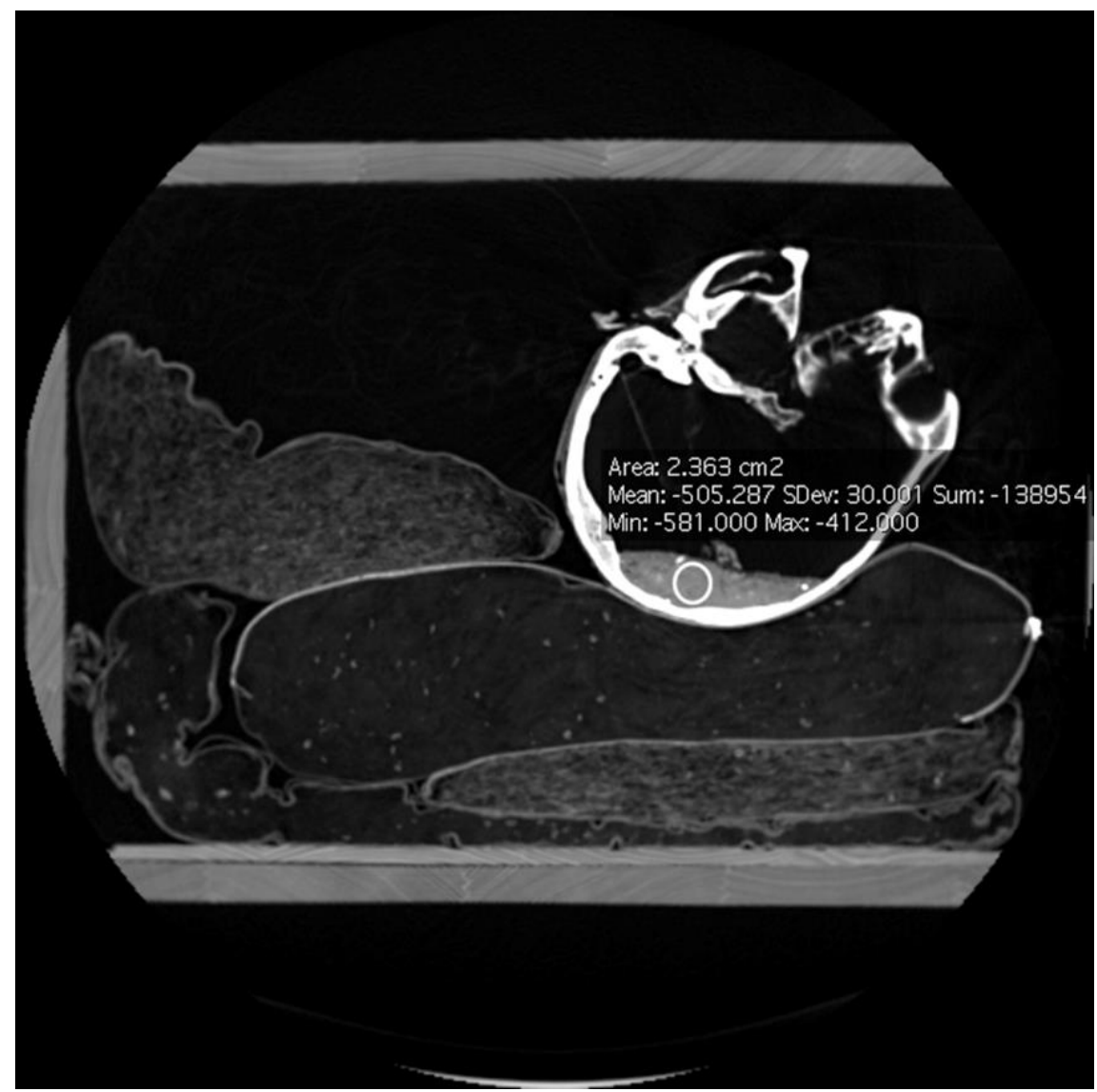

Figure 1. The position of the head and remains of soft tissues.

No pathological and traumatic changes were seen on the remains of the soft tissues. Also, the examination of the body did not reveal any signs of artificial mummification (Jackowski et al., 2008).

All bones were in their anatomical position and completely preserved. The examination of the skeleton revealed pathological changes on the sacrum and the 
I. Kružić, I. Jerković, F. Mihanović, A. Marušić, Š. Anđelinović, Ž. Bašić:

Virtual Autopsy in Legal Medicine: Literature Review and Example of Application on the Mummified Remains

lower limb. The posterior laminae of all the sacral vertebrae were not fused, forming a wide canal. According to Eubanks et al. (Eubanks \& Cheruvu, 2009), the defect would be graded as stage III ("pan-sacral") closure failure (S1-S5 vertebrae). Myelomeningocele, meningocele, or lesions communicating with the environment were not visible so that we made the diagnosis of the spina bifida occulta (a hidden form of the bifid spine) (Figure 2).

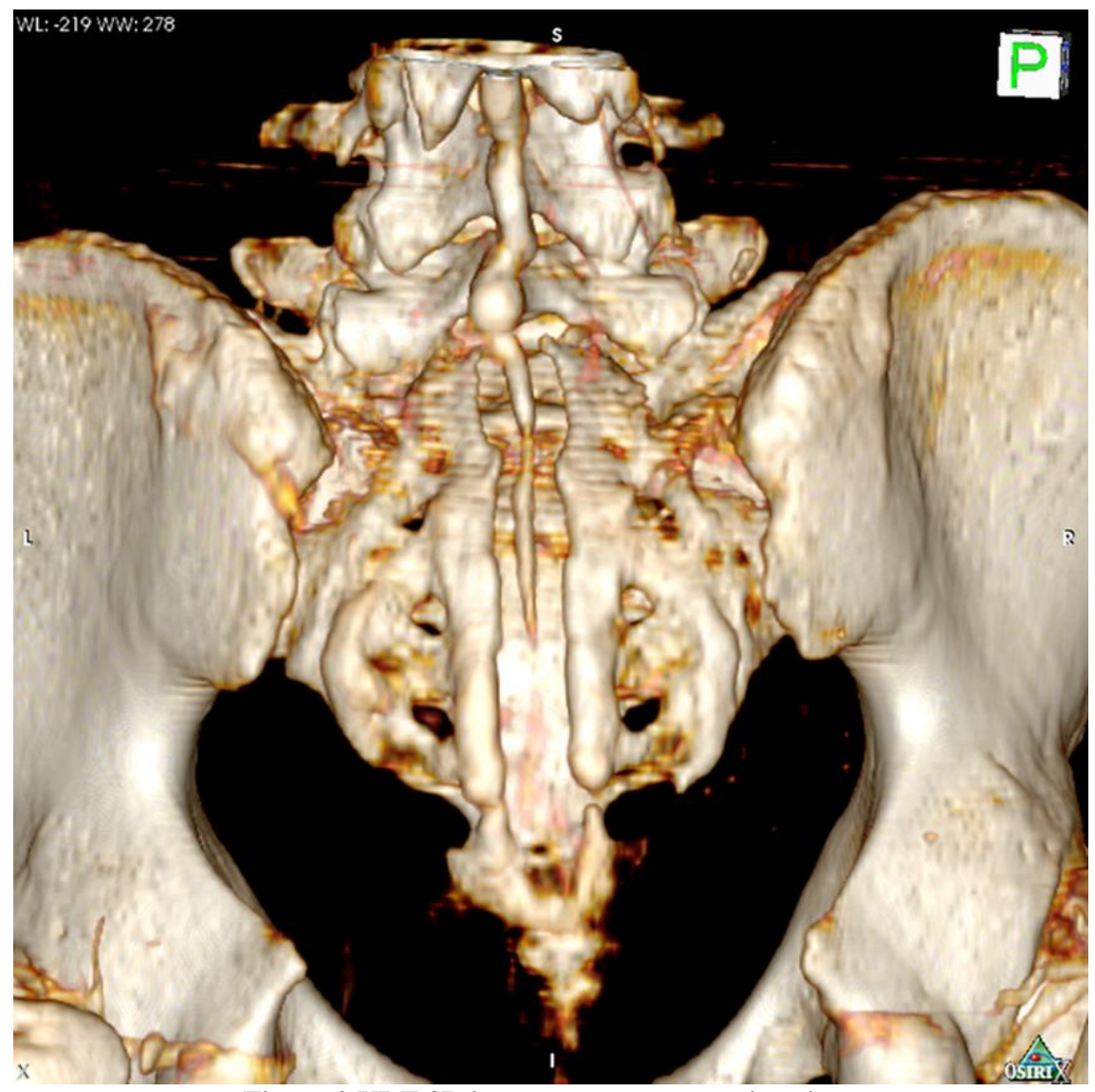

Figure 2.VRT 3D image, sacrum, posterior view.

Also, the rotational deformities of the left hip, the femur, and the tibia were visible (Figures 3 and 4). 
I. Kružić, I. Jerković, F. Mihanović, A. Marušić, Š. Anđelinović, Ž. Bašić:

Virtual Autopsy in Legal Medicine: Literature Review and Example of

Application on the Mummified Remains

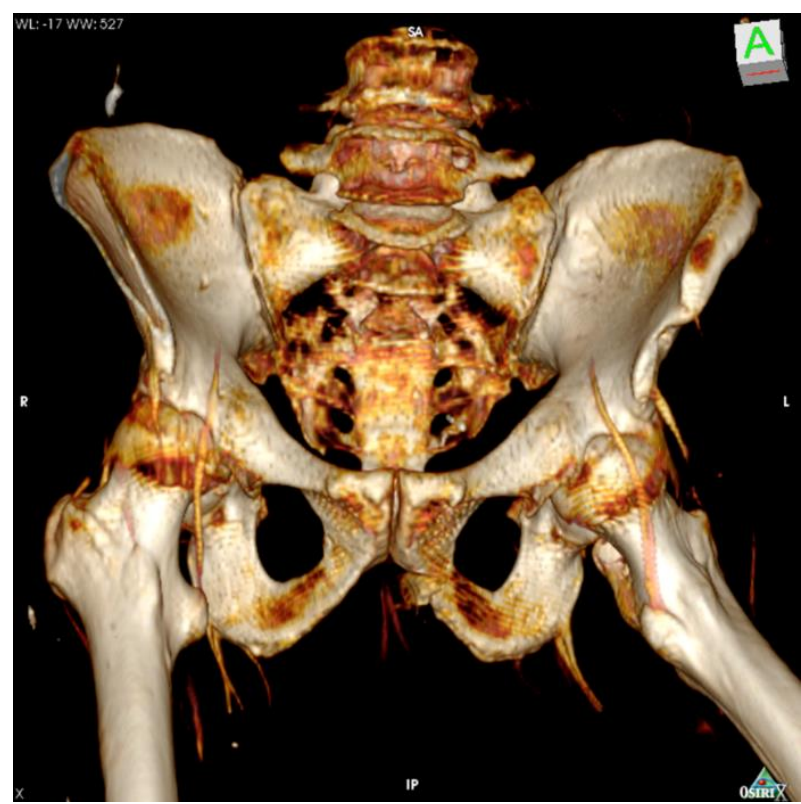

Figure 3. VRT 3D image, anterior view of external rotation of the left hip.

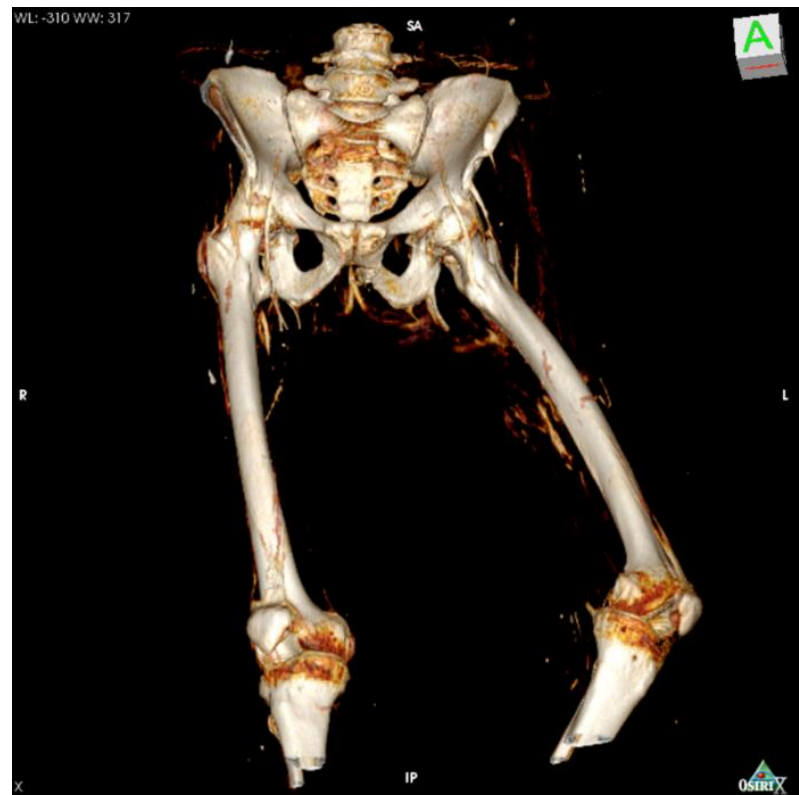

Figure 4.VRT 3D image, anterior view of the lower extremities. 
I. Kružić, I. Jerković, F. Mihanović, A. Marušić, Š. Anđelinović, Ž. Bašić:

Virtual Autopsy in Legal Medicine: Literature Review and Example of Application on the Mummified Remains

We also found clubfoot deformity on the left foot (talipes equinovarus) (Figure 5).

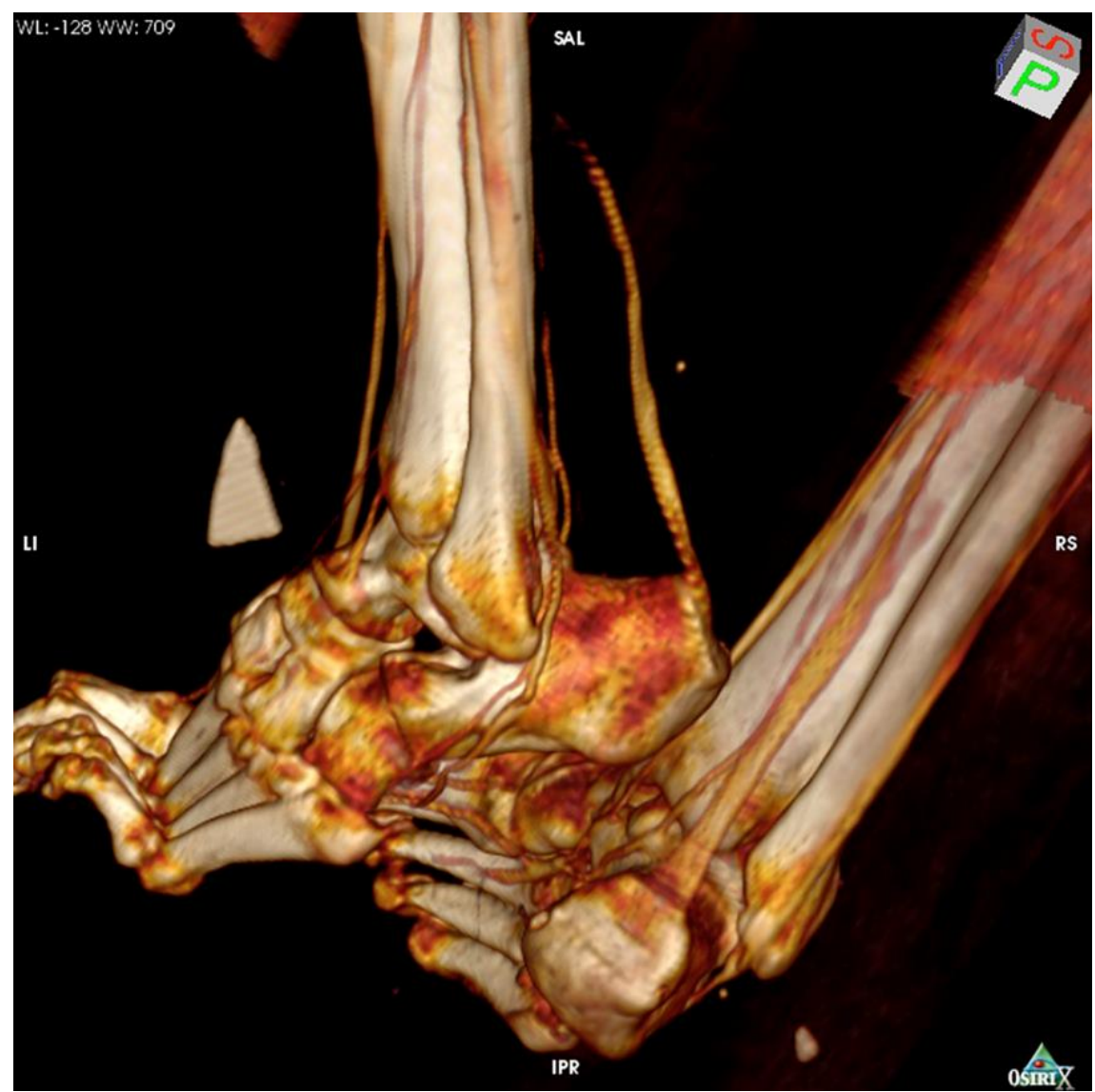

Figure 5.VRT 3D image, deformity of the left foot.

\section{Discussion and conclusion}

In this article, we elaborated upon the possibilities and advantages of implementing methods of virtual autopsy; explored the legal background and practical application of post-mortem imaging methods in Europe; and, presented all steps of the virtual autopsy from the choice of imaging methodology to the final results of the virtual autopsy. Through this broad study, we enabled a wider audience, including forensic, medical, and legal experts to familiarize themselves with the science of forensic imaging and virtual autopsy. This is crucial not only for the continuous development of the methodology but also for acceptance of the methods in practice and for longterm adaptation of legal systems to novel technologies. As a general proposition, 
most legal systems will not find such methods admissible in evidence if they have not gained general acceptance in the scientific community. To the best of our knowledge, this is one of the rare studies that employed an interdisciplinary approach and combined law, theory, and practice to show the possibilities of virtual autopsy. The example that we provided in the study demonstrated that autopsy can be successfully conducted even after seven centuries. Also, the examination of pathological changes and disorders that we found of the mummified body can also be applicable to contemporary forensic cases in the process of identification and analysis of the cause of death.

The virtual autopsy and post-mortem imaging are surely the technology of future. As we demonstrated, these methods have numerous advantages in determining the cause and manner of death, identification, material evidence examination, and interpretation. Additionally, they allow non-destructive analysis, which provides a way of visualization and presentation that could overcome communication problems between forensic and legal experts. However, they suffer from several disadvantages at the moment, which is why they cannot substitute traditional autopsy in all cases. Specifically, virtual autopsy cannot provide information about the odour and texture of organs, as well as volume measurements, which may be of great importance in diagnostics (Bolliger \& Thali, 2015; Jakobsen et al. 2016). Additionally, when dealing with poisoning as the cause of death, virtual autopsy without toxicological analysis is not a viable option (Hayakawa et al., 2006). Also, using only post-mortem imaging poses challenges in ruling out natural causes of death. For example, arrhythmogenic coronary artery disease, which is the prevailing cause of sudden deaths, cannot be determined using virtual autopsy (Bolliger \& Thali, 2015).

One of the closely related limiting factors is also the present lack of information and available sources related to the degree of the inclusion of virtual autopsy and postmortem images in legal regulations and practice. Namely, to the best of our knowledge, at present time the only available source that deals with the legal and practical implications of virtual autopsy and post-mortem imaging is Zimmerman's study (2011), which is at this moment probably outdated. However, the Zimmerman study has inherent limitations because it is based mainly on personal communications and the study of regulations from only a few countries, and those limitations make it impossible to obtain current data without conducting a novel and systematic study of the implementation of virtual autopsy and post-mortem imaging in Europe. According to the Zimmermann study (2011), virtual autopsy and postmortem imaging methods are not represented in laws and regulations, although the application of additional methods, along with traditional autopsy when necessary, is usually permitted. Due the present shortcomings in the law, virtual autopsy methods are probably significantly under used in practice to the extent they could be especially when we consider the advanced state of both their scientific and technical development. Post-mortem imaging is mostly conducted in tandem with 
the traditional autopsy. This is true in some countries always, and in other countries in special cases only. Less frequently, the methods are applied before an autopsy as a triage procedure, in order to decide if a specific case needs an autopsy. Virtual autopsy and post-mortem imaging as standalone methods in most countries are reserved for specific cases, such as high-risk infection, SIDS or mass fatalities (Zimmermann, 2011; Arthurs et al., 2017). The lack of resources and equipment could also be a reason why the post-mortem imaging and virtual autopsy technology is not utilized more frequently. Not all institutions have access to the necessary imaging equipment, and even when they do, the equipment's utility can be limited in an in-hospital setting (Bolliger \& Thali, 2015). This situation is probably mostly the case in smaller countries which have limited resources. One of the important issues is the intention of governmental bodies and legal systems to reduce the cost (Bolliger \& Thali, 2015). However, these institutions often lose sight of the fact that, short-term cost layouts aside, in the long-term, the implementation of postmortem imaging can actually serve to reduce cost (Blokker et al., 2016). This assertion is best confirmed by Zimmermann (2011) with the example of Switzerland, where the price of a complete virtual autopsy is about 5000 AUD (around $2300 €$ ) while the price of a forensic autopsy is around 2500 AUD (about $1600 €)$. But, if we consider that in most cases a CT imaging is sufficient and only costs around 500 AUD (about $320 €$ ) per hour, the application of this technique can lead to a significant price reduction (Zimmermann, 2011). Also, even in cases where imaging is not used instead of traditional autopsy, application of post-mortem imaging in the process of triage could result in price reduction because the number of unnecessary autopsies could be minimized. There are also multiple non-financial benefits associated with imaging that are important for the development of health services and medicine in general. Primarily, it is the possibility of using imaging in the teaching realm and for research purposes, which is also one of the main reasons why scientists need to continually improve virtual autopsy/post-mortem imaging and advocate their application in practice.

The method used for virtual autopsy in the present study showed that the digital images acquired using MSCT were obtainable and of great benefit even when the time lapse from death to imaging was significant and when the body was mummified. The application of MSCT methodology on the body of Ivan Olini revealed that the remains of internal organs, muscles and ligaments were preserved, and as a consequence we were able to access the pathological condition of the remains. Although we used only MSCT, as other methods were non-appropriate, this method was sufficient to perform virtual examination. These results demonstrate the vast potential and utility of the methodology, even in cases where only one of the available methods can be used. Considering the fact that we were dealing with a medieval mummified body, the possibilities of the application of MSCT in the virtual autopsy of recent cadavers are nearly unlimited. One of the additional advantages of these methods is the possibilities presented for the 
education of medical doctors, especially radiologists and legal medical examiners. Our analysis revealed that Ivan Olini's internal organs were preserved, which in turn enabled us to perform the autopsy. Although we have examined the remains of the soft tissues, we have not found any pathological or traumatic changes in them. However, the examination of the skeletal features revealed numerous pathological findings. The first finding was spina bifida occulta on the sacrum. Although the earliest description of bifid spine was published in 1610, and Virchow first described spina bifida occulta in 1875 (Simalcsik et al., 2011), the classification of spinal dysraphism, including bifid spine, was not conceived until 2008 by Sav (2008). He classified spinal dysraphism into three categories: spina bifida cystica, aperta, and occulta. Spina bifida cystica involves myelomeningocele or meningocele; spina bifida aperta involves lesions communicating with the environment; and, spina bifida occulta indicates a hidden form of spinal dysraphism with anomalies located at the bottom of the spine (Sav, 2008). The etiology of this disease is yet unknown, but potential causative factors include the lack of folic acid in pregnancy (MRC Vitamin Study Research Group, 1991), maternal nutritional status, teratogenic factors and genetic factors (Lovett \& Gatrell, 1988). The neural tube closes at the $28^{\text {th }}$ week of intrauterine life and the failure of closure along the spine causes bifid spine (Fishman, 2003). The bifid spine is a very frequent anomaly, and the frequencies of bifid spine vary among the published population data from $1 \%$ to $30 \%$ (Albrecht et al., 2007). Although bifid sacrum is a relatively common finding in the osteological material (around 10\% of specimens) (Ortner, 2003), some authors have found isolated populations that have the prevalence of sacral bifid spine of almost $30 \%$. The most cases of bifid spine on the sacrum reported in archaeological materials are spina bifida occulta (Simalcsik et al., 2011). Some authors have associated bifid spine with other pathologies such as posterior vertebral disk hernia or neurological abnormalities of the legs (Junghanns \& Schmorl, 1971) while some reported the cases with progressive deformities of a lower limb (Brailsford, 1953). Other authors have demonstrated that patients with bifid spine have several hip, knee and ankle rotational deformities. These deformities can be either acquired or congenital. Some of the congenital deformities include kyphosis, hip dislocations, clubfoot and rotational deformities of the lower extremities. The acquired hip developmental deformities are usually caused by the muscle imbalance and paralysis around the hip joint and can involve contracture, subluxation, and dislocation. The knee can be affected by the flexion, extension, valgus, instability and pain, which is the result of numerous factors such as static forces of positioning, fibrosis of surrounding muscles, muscle imbalance and fracture malunion. The bifid spine in the low lumbar area usually presents with associated valgus knee deformity (Swaroop \& Dias, 2009). The bifid spine can also be accompanied with tibial torsion, which is then considered as part of a congenital deformation (Swaroop and Dias, 2009). In the present study we found the bifid spine, rotational deformities of the hip, femur, and tibia, as well as the clubfoot, which indicates that those pathological changes were probably a consequence of a congenital deformation. 
The case of the mummified body of Ivan Olini showed that the application of the whole body MSCT, even without the use of other imaging techniques, can be sufficient for drawing conclusions about the pathological changes and state of preservation. Considering that the analysis was useful in historical person analysis, its usefulness in the present day forensic context would be significantly greater, as the analysis can provide nearly endless data on diseases and trauma and can serve for comparative identification when ante-mortem data are available.

Taking into the consideration the advantages of the virtual autopsy, post-mortem imaging techniques, and the results of the present study, we strongly recommend that virtual autopsy should be used to a much greater extent both in legal medicine and anthropology. One of the major initial steps in this process is to implement at least MSCT imaging in forensic cases before employing a traditional autopsy or as an adjunct method. This way we could enhance the quality of the results and their presentation in particular cases, provide the possibility of second opinions and also contribute substantially both to the long-term development of this methodology and cost reduction. Also, when these methods are used more frequently in practice it will enrich knowledge of the scientists and practitioners and probably become a standard method in forensic pathology and radiology.

\section{References}

Albrecht, T. L., Scutter, S. \& Henneberg, M (2007) Radiographic method to assess the prevalence of sacral spina bifida occulta, Clinical Anatomy, 20 (2), pp. 170-174, doi: 10.1002/ca.20367.

Appleby, J., Rutty, G. N., Hainsworth, S. V., Woosnam-Savage, R. C., Morgan, B., Brough, A., Earp, R. W., Robinson, C., King, T. E. \& Morris, M (2015) Perimortem trauma in King Richard III: a skeletal analysis, The Lancet, 385(9964), pp. 253-259, doi: 10.1016/S0140-6736(14)60804-7.

Arthurs, O. J., Hutchinson, J. C. \& Sebire, N. J. (2017) Current issues in postmortem imaging of perinatal and forensic childhood deaths, Forensic Science, Medicine and Pathology, 13(1), pp. 58-66., doi: 10.1007/s12024-016-9821-x.

Baier, W., Warnett, J. M., Payne, M. \& Williams, M. A. (2017) Introducing 3d printed models as demonstrative evidence at criminal trials, Journal of Forensic Sciences, 63(4), doi: 10.1111/1556-4029.13700.

Blokker, B. M., Wagensveld, I. M., Weustink, A. C., Oosterhuis, J. W, \& Hunink, M. M. (2016) Non-invasive or minimally invasive autopsy compared to conventional autopsy of suspected natural deaths in adults: a systematic review, European radiology, 26(4), pp. 1159-1179, doi: 10.1007/s00330-015-3908-8.

Blum, A., Kolopp, M., Teixeira, P. G., Stroud. T., Noirtin, P., Coudane, H., \& Martrille, L. (2018) Synergistic Role of Newer Techniques for Forensic and Postmortem CT Examinations, American Journal of Roentgenology, 211, pp. 3-10, doi: 10.2214/AJR.17.19046. 
Bolliger, S. A. \& Thali, M. J. (2015) Imaging and virtual autopsy: looking back and forward, Philosophical Transactions of the Royal Society B: Biological Sciences, 370(1674), pp. 20140253, doi: 10.1098/rstb.2014.0253.

Brailsford, J. (1953) The Radiology of Bones and Joints (London: Churchill).

Bushong, S. C. (2013) Radiologic Science for Technologists-E-Book: Physics, Biology, and Protection (Elsevier Health Sciences).

Cobo, F. B. (2010) Inca religion and customs (Texas: University of Texas Press).

Cosmacini, P. \& Piacentini, P. (2008) Notes on the history of the radiological study of Egyptian mummies: from X-rays to new imaging techniques, La radiologia medica, 113 (5), pp. 615-626, doi: 10.1007/s11547-008-0280-7.

Davey, J., Stewart, M. E. B. \& Drummer, O. H. (2013) The value of CT imaging of Horus in determining the method of mummification and the sex of the mummy, Journal of medical imaging and radiation oncology, 57(6), pp. 657-662, doi: 10.1111/17549485.12070.

Dedouit, F., Géraut, A., Baranov, V., Ludes, B., Rougé, D., Telmon, N. \& Crubézy, E. (2010) Virtual and macroscopical studies of mummies-Differences or complementarity? Report of a natural frozen Siberian mummy, Forensic science international, 200, pp. e7-e13, doi: 10.1016/j.forsciint.2010.03.028.

Dedouit, F., Guglielmi, G., Perilli, G., Nasuto, M., Telmon, N., Fineschi, V. \& Pomara, C. (2014a) Virtual anthropological study of the skeletal remains of San Fortunato (Italy, third century AD) with multislice computed tomography, Journal of Forensic Radiology and Imaging, 2(1), pp. 9-16, doi: 10.1016/j.jofri.2013.11.006.

Dedouit, F., Savall, F., Mokrane, F., Rousseau, H., Crubézy, E., Rouge, D. \& Telmon, N. (2014b) Virtual anthropology and forensic identification using multidetector CT, The British journal of radiology, 87(1036), 20130468, doi: 10.1259/bjr.20130468.

Del Ton, G. (1929) Cenni storici sui 'Corpi Santi' di Dignano (Poreč).

DiMaio, V. J. \& Francis, J. R. (2001) Heterotopic ossification in unidentified skeletal remains, The American journal of forensic medicine and pathology, 22(2), pp. 160164.

Ebert, L., Flach, P., Schweitzer, W., Leipner, A., Kottner, S., Gascho, D., Thali, M. \& Breitbeck, R. (2016) Forensic 3D surface documentation at the Institute of Forensic Medicine in Zurich-Workflow and communication pipeline, Journal of Forensic Radiology and Imaging, 5, pp. 1-7.

Eeckhout, P. \& Owens, L. S. (2008) Human sacrifice at Pachacamac, Latin American Antiquity, 19(4), pp. 375-398, doi: 10.1017/S104566350000434X.

Eubanks, J. D. \& Cheruvu, V. K. (2009) Prevalence of sacral spina bifida occulta and its relationship to age, sex, race, and the sacral table angle: an anatomic, osteologic study of three thousand one hundred specimens, Spine, 34(15), pp. 1539-1543, doi: 10.1097/BRS.0b013e3181a98560.

Fernando, L. (2008) Place of autopsy in quality assurance of curative service, Galle Medical Journal, 13, pp. 51-54, doi: 10.4038/gmj.v13i1.897.

Fishman, M. (2003) Disturbances in neural tube closure and spine and cerebrospinal fluid dynamics (New York: McGraw-Hill Medical Publishing Division).

Fulcheri, E. (1996) Mummies of Saints: a particular category of Italian mummies, In: Spindler, K. (eds.) [et al.] Human Mummies: A Global Survey of their Status and the Techniques of conservation (Vienna: Springer), pp. 219-230.

Gascho, D., Philipp, H., Flach, P. M., Thali, M. J. \& Kottner, S. (2018) Standardized medical image registration for radiological identification of decedents based on paranasal 
I. Kružić, I. Jerković, F. Mihanović, A. Marušić, Š. Anđelinović, Ž. Bašić: Virtual Autopsy in Legal Medicine: Literature Review and Example of Application on the Mummified Remains

sinuses, Journal of Forensic and Legal Medicine, 54, pp. 96-101, doi: 10.1016/j.jflm.2017.12.003.

Garetier, M., Deloire, L., Dédouit, F., Dumousset, E., Saccardy, C., \& Salem, D. B ( 2017) Postmortem computed tomography findings in suicide victims, Diagnostic and interventional imaging, 98(2), pp. 101-112, doi: 10.1016/j.diii.2016.06.023.

Hayakawa, M., Yamamoto, S., Motani, H., Yajima, D., Sato, Y, \& Iwase, H. (2006) Does imaging technology overcome problems of conventional postmortem examination?, International journal of legal medicine, 120(1), pp. 24-26, doi: 10.1007/s00414-0050038-x.

Hawass, Z., Gad, Y. Z., Ismail, S., Khairat, R., Fathalla, D., Hasan, N., Ahmed, A., Elleithy, H., Ball, M. \& Gaballah, F. (2010) Ancestry and pathology in King Tutankhamun's family, JAMA, 303(7), pp. 638-647, doi: 10.1001/jama.2010.121.

Iscan, M. Y. \& Steyn, M. (2013) The human skeleton in forensic medicine (Charles C Thomas Publisher).

Jakobsen, L. S., Lundemose, S., Banner, J., Lynnerup, N., \& Jacobsen, C. (2016) Forensic postmortem computed tomography: volumetric measurement of the heart and liver, Forensic science, medicine, and pathology, 12(4), pp. 510-516, doi: 10.1007/s12024016-9810-0.

Jackowski, C., Bolliger, S. \& Thali, M. J. (2008) Common and unexpected findings in mummies from ancient Egypt and South America as revealed by CT, Radiographics, 28(5), pp. 1477-1492, doi: 10.1148/rg.285075112.

Jelenić, M. (2000) Čudo u Vodnjanu (Vodnjan: Program Mi).

Johnson, R. J., Feehally, J. \& Floege, J. (2014) Comprehensive Clinical Nephrology E-Book (Elsevier Health Sciences).

Junghanns, H. \& Schmorl, G. (1971) The human spine in health and disease (Oxford: Oxford University Press).

Krentz, B. V., Alamo, L., Grimm, J., Dédouit, F., Bruguier, C., Chevallier, C., Egger, C., Da Silva, L. F., \& Grabherr, S. (2016) Performance of post-mortem CT compared to autopsy in children, International journal of legal medicine, 130(4), pp. 1089-1099, doi: 10.1007/s00414-016-1370-z.

Kristóf, L. A., Kovács, M., Baksa, G., Bereczki, Z., Szatmári, F., Patonay, L., Pálfi, G. \& Pohárnok, L. (2015) Condition assessment of two early Christian martyrs', St. Christine's and St. Augustine's relics with paleoradiological methods in Hungary, Journal of Cultural Heritage, 16(2), pp. 249-253, doi: 10.1016/j.culher.2014.04.001.

Ling, T. (2010) How Do You Get Clinicians Involved in Quality Improvement?: An Evaluation of the Health Foundation's Engaging with Quality Initiative: A Programme of Work to Support Clinicians to Drive Forward Quality (The Health Foundation).

Liu, C., \& He, H. (2018) Developments and Applications of Calcium Phosphate Bone Cements (Singapore: Springer).

Lovett, A. A. \& Gatrell, A. C. (1988) The geography of spina bifida in England and Wales, Transactions of the Institute of British Geographers, 13(3), pp. 288-302, doi: $10.2307 / 622992$.

Lynnerup, N. (2010) Medical imaging of mummies and bog bodies-a mini-review, Gerontology, 56(5), pp. 441-448, doi: 10.1159/000266031.

Makino, Y., Yokota, H., Nakatani, E., Yajima, D., Inokuchi, G., Motomura, A., Chiba, F., Torimitsu, S., Uno, T., \& Iwase, H. (2017) Differences between postmortem CT and 
autopsy in death investigation of cervical spine injuries, Forensic Science International, 281, pp. 44-51, doi: 10.1016/j.forsciint.2017.10.029.

Markel, H. (2010) King Tutankhamun, Modern Medical Science, and the Expanding Boundaries of Historical Inquiry, JAMA, 303(7), pp. 667-668, doi: 10.1001/jama.2010.153.

MRC Vitamin Study Research Group (1991) Prevention of neural tube defects: results of the Medical Research Council Vitamin Study, The Lancet, 338(8760), pp. 131-137.

Mihanović, F., Jerković, I., Kružić, I., Anđelinović, Š., Janković, S. \& Bašić, Ž. (2017) From biography to osteobiography: an example of anthropological historical identification of the remains of St. Paul, The Anatomical Record, 300(9), pp. 1535-1546, doi: 10.1002/ar.23602.

Mohammed, M. \& Kharoshah, M. A. (2014) Autopsy in Islam and current practice in Arab Muslim countries, Journal of forensic and legal medicine, 23, pp. 80-83, doi: 10.1016/j.jflm.2014.02.005.

Nissan, E. (2012) Virtopsy: The Virtual Autopsy, Computer Applications for Handling Legal Evidence, Police Investigation and Case Argumentation (Springer).

Öhrström, L. M., von Waldburg, H., Speier, P., Bock, M., Suri, R. E. \& Rühli, F. J. (2013) Scenes from the past: MR imaging versus CT of ancient Peruvian and Egyptian mummified tissues, Radiographics, 33(1), pp. 291-296., doi: 10.1148/rg.331125711.

Ortner, D. J. (2003) Identification of pathological conditions in human skeletal remains (Academic Press).

Panzer, S., Borumandi, F., Wanek, J., Papageorgopoulou, C., Shved, N., Colacicco, G. \& Rühli, F. J. (2013a) "Modeling ancient Egyptian embalming": radiological assessment of experimentally mummified human tissue by CT and MRI, Skeletal radiology, 42(11), pp. 1527-1535, doi: 10.1007/s00256-013-1696-2.

Panzer, S., Gill-Frerking, H., Rosendahl, W., Zink, A. R. \& Piombino-Mascali, D. (2013b) Multidetector CT investigation of the mummy of Rosalia Lombardo (1918-1920). Annals of Anatomy-Anatomischer Anzeiger, 195(5), pp. 401-408, doi: 10.1016/j.aanat.2013.03.009.

Payne-James, J., McGovern, C., Jones, R., Karch, S. \& Manlove, J. (2014) Simpson's Forensic Medicine: Irish Version (CRC Press).

Petaros, A., Škrobonja, A. \& Bosnar, A. (2012) Mummified saints of the Northern Croatian Littoral, Acta Medico-Historica Adriatica, 10(1), pp. 131-140.

Pettersson, H. \& Allison, D. J. (1998) The encyclopaedia of medical imaging (Nicer Institute).

Ross, S. G., Bolliger, S. A., Ampanozi, G., Oesterhelweg, L., Thali, M. J. \& Flach, P. M. (2014) Postmortem CT angiography: capabilities and limitations in traumatic and natural causes of death, Radiographics, 34(3), pp. 830-846, doi: 10.1148/rg.343115169.

Saleem, S. N. \& Hawass, Z. (2014) Multidetector computed tomographic study of amulets, jewelry, and other foreign objects in royal Egyptian mummies dated from the 18th to 20th dynasties, Journal of computer assisted tomography, 38(2), pp. 153-158, doi: 10.1097/RCT.0b013e3182ab2221.

Sav, A. (2008) Pathological anatomy of spina bifida, In: The Spina Bifida (Springer, Milano), pp. 43-57.

Schweitzer, W., Thali, M., Breitbeck, R. \& Ampanoz, G. (2014) Virtopsy®, available at: https://www.researchgate.net/publication/281756753_VirtopsyR (September 13, 2018). 
Simalcsik, A., Miu, G., Groza, V.-M. \& Simalcsik, R.-D. (2011) Regarding occult spinal dysraphism (spina bifida occulta), focusing especially on a medieval population from Iași, Analele șt. Univ. “Al. I. Cuza” Iași, s. I, Biologie animală, pp. 131-140.

Swaroop, V. T. \& Dias, L. (2009) Orthopedic management of spina bifida. Part I: hip, knee, and rotational deformities, Journal of children's orthopaedics, 3(6), pp. 441-449, doi: 10.1007/s11832-009-0214-5.

Thali, M., Dirnhofer, R. \& Vock, P. (2009) The virtopsy approach: 3D optical and radiological scanning and reconstruction in forensic medicine (CRC Press).

Thali, M. J., Viner, M. D. \& Brogdon, B. G. (2010) Brogdon's forensic radiology (CRC Press).

Tuchtan, L., Gorincour, G., Kolopp, M., Massiani, P., Léonetti, G., Piercecchi-Marti. M., \& Bartoli, C. (2017). Combined use of postmortem 3D computed tomography reconstructions and 3D-design software for postmortem ballistic analysis, Diagnostic and Interventional Imaging, 98(11), pp. 809-812, doi: 10.1016/j.diii.2017.06.016.

van Kan, R., Haest, I., Lahaye, M., \& Hofman, P. (2017) The diagnostic value of forensic imaging in fatal gunshot incidents: A review of literature, Journal of Forensic Radiology and Imaging, 10, pp. 9-14, doi: 10.1016/j.jofri.2017.07.003.

Zimmermann, D. (2011) Virtopsy \& forensic imaging: legal parameters and impact. AsiaPacific Coroners Society Conference 2011 Noosa, Queensland, available at: https://www.courts.qld.gov.au/_data/assets/pdf_file/0006/163761/osc-asia-pacificconference-00-zimmermann-d.pdf (September 13,2018 ). 

